\title{
Artigos
}

Tauana Olívia Gomes Silva

Universidade Federal de Santa Catarina, Florianópolis, SC, Brasil

Gleidiane de Sousa Ferreira

Universidade Federal de Santa Catarina, Florianópolis, SC, Brasil

\section{E as mulheres negras? Narrativas históricas de um feminismo à margem das ondas}

Resumo: Neste texto refletimos as seguintes perguntas: onde estão as mulheres negras nas narrativas hegemônicas sobre os movimentos de mulheres e feministas brasileiros? Até que ponto os limites teóricos e os caminhos metodológicos que constituem boa parte da historiografia do feminismo e da luta das mulheres da primeira metade do século XX no Brasil não nos permitiram, ou não nos foram suficientes, para refletir as trajetórias de lutas das mulheres negras? Afinal, qual a história das pautas e reivindicações feministas? Ou melhor, como essa história é contada?

Palavras-chave: história do feminismo; mulheres negras; trajetórias de vida

Desde que chegaram ao Brasil, as africanas e depois suas descendentes, tiveram a necessidade de lutar pela liberdade e por melhores condicões de vida. Schuma Schumaher e Erico Vital Brazil, 2007, p. 91

Os anos 1950 foram marcados por uma grande mobilização das mulheres brasileiras em torno de associações e conselhos, congressos nacionais e internacionais, campanhas pela paz, pela infância e contra a carestia. Elas se envolveram em muitas campanhas cívicas e se engajaram contra a repressão política que caracterizava esse momento, especialmente com a chamada "Guerra Fria".

Partindo da pesquisa inicial que culminou neste artigo foi possível observar a importante participação das mulheres negras nessas mobilizações políticas. Em 1950, por exemplo, elas são numerosas nas reuniões da Convenção Feminina de Vitória, organizada pela Federação de Mulheres do Brasil; e, também, nas reuniões da Associação Feminina

\section{(c) ()}

Esta obra está sob licença Creative Commons. 
do Distrito Federal e da União Feminina do Morro da Favela, como podemos ver no jornal Momento Feminino (1950b, p. 12).

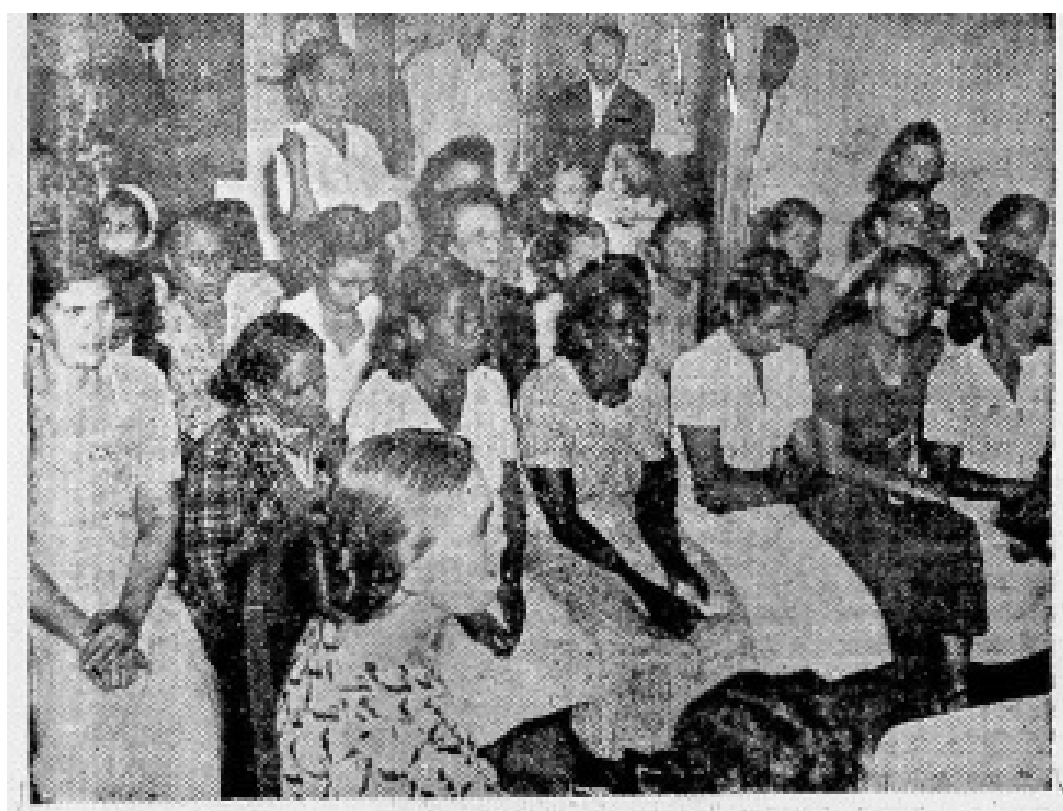

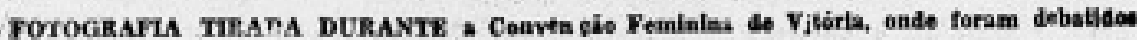
of problemas eae mals anirem as melheres explehabas.

MOMENTO FEMININO. Rio de Janeiro, ano III, n. 73, 1 de agosto de 1950b.

Nesse sentido, nos perguntamos: onde estão as mulheres negras nas narrativas hegemônicas sobre os movimentos de mulheres e feministas brasileiros? Teriam elas, mais do que expresso na frase "também existiam negras nesse período", se organizado como uma coletividade de mulheres que se reconheciam como negras? Até que ponto os limites teóricos e os caminhos metodológicos que constituem boa parte da historiografia do feminismo e da luta das mulheres da primeira metade do século XX no Brasil não nos permitiram, ou não nos foram suficientes, para refletir as trajetórias de lutas das mulheres negras? Ou mesmo compreender que suas lutas estavam marcadas ou dialogavam com as pautas feministas de até então? Afinal de contas, qual a história das pautas e reivindicações feministas? Ou melhor, como essa história é contada?

Partindo dessas provocações iniciais e também de vivências políticas que superam a extensão deste trabalho, pretendemos contribuir para uma maior visibilidade das mulheres negras no processo de construção da luta de movimentos de mulheres e feministas na história do Brasil e lançar algumas questões para que as perguntas lançadas nesta introdução possam ser pensadas em outros trabalhos. O texto pretende colocar em evidência a participação política das mulheres negras nesses movimentos, especialmente os que eclodiram no início da década de 1950, além de pensá-las em diálogo com as narrativas hegemônicas sobre o feminismo e suas pautas.

Analisaremos neste artigo a trajetória de três mulheres negras: Maria Rita Soares de Andrade, feminista e militante da FBPF, foi a primeira juíza federal do Brasil, atuou 
principalmente nas áreas do direito, da educação e do jornalismo; Maria Brandão dos Reis e Maria José Camargo de Aragão, que atuaram no interior da Federação de Mulheres do Brasil (FMB) e do Partido Comunista Brasileiro (PCB), especialmente em prol das mulheres de classes baixas. Participaram de vários movimentos sociais nos anos 1950, sobretudo das mobilizações pela paz e contra a carestia.

Conhecer as trajetórias políticas dessas mulheres foi possível através de uma pesquisa realizada em diferentes jornais da imprensa nacional disponíveis na hemeroteca da Biblioteca Nacional e que serviram como um caminho metodológico para entendermos a frequência e o modo como elas aparecem na cena pública por meio do discurso da imprensa do período. É através das trajetórias e inserções políticas dessas mulheres que gostaríamos de convidar as leitoras a refletir sobre as histórias acerca do feminismo brasileiro, suas narrativas e seus diferentes significados. Sabemos dos limites dessa empreitada, visto que o/a leitor/a deve observar as complexidades de se pensar a visibilidade dessas mulheres negras em relação às narrativas hegemônicas dos movimentos de mulheres e feministas. Porém, essa foi uma escolha que entendemos ser viável para o artigo e esperamos que suas ausências possam provocar debates e outras escrituras sobre esses temas e questões, sendo um deles o próprio diálogo com os feminismos negros que optamos por não realizar aqui, apesar de sabermos de sua importância para pensar política e ideologicamente a participação delas nesse momento e espaços.

\section{A trajetória política de Maria Rita Soares de Andrade}

Nos anos 1920, duas mulheres negras, Almerinda Farias Gama' e Maria Rita Soares de Andrade, ${ }^{2}$ contribuíram na criação da Federação Brasileira para o Progresso Feminino (FBPF). ${ }^{3}$ Maria Rita Soares de Andrade foi secretária e assistente jurídica de tal federação durante muitos anos. Em 1951, coube à Maria Rita, então presidente da FBPF, pronunciar o discurso de agradecimento pela assinatura do ato que aprovou o texto da Comissão Interamericana de Mulheres sobre a concessão dos direitos civis às mulheres. ${ }^{4}$ Durante seu discurso, Maria Rita rememorou as vitórias das mulheres, porém acrescentou a necessidade da continuidade do engajamento político. Para ela, essas conquistas ainda não representavam todos os anseios do pensamento feminino e ainda havia reivindicações a serem encaminhadas à Comissão do Senado estabelecida para esses fins. Segundo o Correio da Manhã (1951),

[...] seu discurso foi um tanto ríspido para com os homens. Fez também severas críticas ao período ditatorial do sr. Getúlio Vargas, na opinião da oradora o anjo negro do feminismo. Disse que as mulheres foram a vanguarda do golpe de 29 de outubro [...].

\footnotetext{
' Almerinda Farias Gama, na qualidade de presidente do Sindicato das Datilógrafas e Taquígrafas do Distrito Federal, foi a primeira e única mulher a votar na Assembleia Nacional Constituinte de 1933 (SCHUMAHER; BRAZIL, 2007, p. 317).

${ }^{2}$ Essas militantes faziam parte de uma classe média intelectualizada que certamente fora determinante para que a vida pública dessas mulheres pudesse ganhar alguma visibilidade. Apesar de não termos maiores informações sobre elas, é possível pensar que tiveram, ao contrário de muitas mulheres pobres, negras ou brancas, a possibilidade de participar da vida política da sociedade brasileira. Essa participação destas costumava ficar cerceada pelas triplas ou quádruplas jornadas de trabalho.

${ }^{3}$ Essa federação foi registrada em São Paulo em 1922 com o objetivo de lutar pelos direitos da "mulher brasileira" e divulgar o ideário feminista nos espaços oficiais de poder. A protagonista que teve mais visibilidade foi a sufragista branca, da classe alta paulista, Bertha Lutz.

${ }^{4} \mathrm{Em}$ maio de 1948, em Bogotá, durante a IX Conferência Internacional Americana, foi assinada a Convenção Interamericana sobre a Concessão dos Direitos Políiticos da Mulher. Ela foi ratificada pelo Brasil em 15 de fevereiro de 1950.
} 
Pediu que aquele documento firmado pelo sr. Café Filho ${ }^{5}$ não constituísse letra morta, como tudo que se faz no Brasil. Alegou que as mulheres recebem muito pouco dos homens e as suas conquistas são feitas palmo a palmo (p. 10).

Refletindo o pequeno trecho do discurso reproduzido no jornal, que se materializava depois do retrocesso dos direitos das mulheres após a ditadura varguista, é possível perceber a desconfiança por parte da oradora em relação aos poderes públicos e a conquista dos direitos das mulheres. Essa desconfiança se contrasta com a fé recorrentemente expressada pela bióloga Bertha Lutz em momentos anteriores, que representava a conquista dos direitos

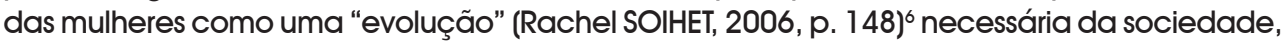
como uma "força" quase inevitável nas democracias mundiais, e que, portanto, o Brasil não deveria ignorar.

Em 1954, Maria Rita aparecia novamente nas páginas da imprensa carioca. Demonstrando sua oposição à aproximação das mulheres com o comunismo, foi uma das signatárias do Manifesto das Associações Femininas de Mulheres e Senhoras que se apresentava contra a convocação da Conferência Latino-Americana de Mulheres, prevista para acontecer na cidade do Rio de Janeiro entre os dias 7 a 31 de agosto do mesmo ano. No documento lido no Senado, a Conferência foi citada como um evento que "Moscou mandou realizar no Brasil" (Correio da Manhã, 1954, p. 3). Nesse período, vários movimentos de mulheres foram apontados como agentes diretos do comunismo e sofreram perseguições políticas. O jornal Imprensa Popular do Rio de Janeiro mostrava o clima de insegurança durante a instalação do I Congresso de Mulheres em 1951, na cidade de São Paulo, assim como a resistência e o otimismo das organizadoras.

É intenso o entusiasmo em torno desse grandioso conclave cuja propaganda atingiu os bairros, subúrbios, fábricas, escritórios, repartições, favelas e vilas operárias. [...] A Comissão Organizadora do Congresso, as diretorias da Federação de Mulheres do Brasil [...], apoiadas por todas as delegações congressionais e confiantes no apoio das mulheres e do povo paulista, não se deixou intimidar com as ameaças policiais e nem tão pouco pelas notas provocativas distribuídas à imprensa de aluguel pelo DOPS. O conclave será realizado, conforme já o afirmou a sra. Branca Fialho, que o presidirá (IMPRENSA POPULAr, 1951b, p. 1).

A prisão da comunista e militante da Federação de Mulheres do Brasil (FMB), Elisa Branco, também foi severamente criticada por parte de diferentes movimentos políticos e de mulheres. A principal razão da condenação de Elisa foi sua ativa participação na Campanha pela Paz e na luta contra o envio de soldados brasileiros para combater na Coréia. Durante uma manifestação no ano de 1950, ela abriu uma faixa com a frase: "Os soldados, nossos filhos, não irão para a Coréia" (IMPRENSA POPULAR, 1951 a, p. 1). A condição de "comunista" da militante Elisa Branco fazia com que esta fosse compreendida como um exemplo da infiltração dessa ideologia na luta das mulheres. ${ }^{7}$

O posicionamento de Maria Rita como militante da FBPF se relacionava ao contexto de radicalização política e ideológica dos anos 1950, em que as tensões entre as ideologias pró-comunistas e pró-capitalistas estiveram fortemente em pauta no cenário político

${ }^{5}$ Assinatura do texto da Comissão Interamericana de Mulheres. No caso do Brasil, ele foi elaborado pelo Comitê Brasileiro da Comissão Interamericana de Mulheres, conjuntamente ao Conselho Nacional de Mulheres. ${ }^{\circ}$ Discurso de posse da deputada Bertha Lutz na Câmara dos Deputados (Boletim da FBPF, n. ${ }^{\circ 7}$, junho de 1936 , p. 3-4). Para pensar mais as lutas pacifistas encabeçadas por feministas do início do século XX no Brasil, ver: Miriam Moreira LEITE (1984).

7 O posicionamento de Maria Rita como militante da FBPF se relacionava ao contexto de radicalização políitica e ideológica dos anos 1950, em que as tensões entre as ideologias pró-comunistas e pró-capitalistas estiveram fortemente em pauta no cenário político brasileiro. 
brasileiro. ${ }^{8}$ Para ela, a inserção dos(as) comunistas nas organizações era um fator permanente de perturbação da ordem social. O Manifesto das Associações Femininas de Mulheres e Senhoras incita então "[...] a mulher brasileira a levantar sua voz e sua ação contra a infiltração comunista em nosso meio, a enfrentar o poderio econômico, político e social com que esse grupo aparece hoje [1954] no Brasil [...]" (CORREIO DA MANHÃ, 1954, p. 3).

Considerando a misoginia e o racismo que sempre fizeram parte das esferas políticas da sociedade brasileira, é possível indicar que, apesar da importância de Maria Rita na reconhecida FBPF, sua trajetória política foi marcada por objeções à sua posição enquanto mulher negra. Maria Rita, que era militante da FBPF, mas também da União Universitária Feminina e do Conselho Nacional de Mulheres, nesse quadro de polarizações ideológicas encontrou um importante espaço de expressão e participação política, assumindo, cada vez mais, uma postura liberal e de crítica ao comunismo.

Nas eleições de outubro 1954, Maria Rita apresentou-se como candidata a Deputada Federal pela UDN, partido de orientação conservadora. Segundo o Jornal do Brasil, ela também foi uma das fundadoras do partido e participou da convenção que estruturou seus primeiros estatutos (1954a, p. 6). Durante a campanha contra Getúlio Vargas, para que esse renunciasse ao cargo da Presidência da República, Maria Rita foi uma das referências políticas nos comícios realizados pela UDN. Após o atentado contra o jornalista Carlos Lacerda (UDN), declarado adversário de Vargas, ela participou de um ato cívico ao lado do brigadeiro Eduardo Gomes, do marechal Dutra e do general Juarez.

No dia 27 de agosto de 1954, alguns dias após o suicídio de Vargas, Maria Rita fez uma palestra no programa "Fala a UDN", da Rádio Globo. Os principais temas tratados foram: o luto da nação, a atitude decisiva das Forças Armadas frente à ameaça de conturbação geral e de guerra civil, seu apoio ao vice-presidente João Café Filho e o combate à miséria como objetivo primordial do novo presidente.

Em seguida, o jornal Correio da Manhã indica a presença de Maria Rita em audiência com Café Filho. Acompanhada de outras militantes como Romi Medeiros da Fonseca, Iracy Doyle e Leonisia Queiroz de Azeredo, ela falou durante a audiência em nome do Conselho Nacional de Mulheres. Maria Rita expôs ao presidente sua incompreensão quanto à ausência do elemento feminino nos postos de alta responsabilidade do governo, e suas aspirações de que o mesmo "romperá com esse tabu contra a mulher" (JORNAL DO BRASIL, 1954c, p. 8). Segundo o jornal, ela também assinalou vários problemas de administração, assim como a necessidade da colaboração da mulher nos assuntos que dizem respeito ao trabalho desta e dos filhos, e ao custo de vida.

No final de1955 o presidente Café Filho teve que se afastar do cargo por causa de um problema de saúde. No dia 8 de novembro de 1955, Carlos Luz, presidente da Câmara, assumiu então o posto presidencial. Em seguida, o general Henrique Lott pretendia conduzir um golpe contra o atual presidente e, nesse contexto, Café Filho manifestou novamente o interesse em reassumir o posto presidencial. Porém, este foi vetado por Lott e outros generais que preferiram entregar o mandato a Nereu Ramos, presidente do Senado. No dia 22 de novembro, o Congresso Nacional aprovou o impedimento de Café Filho ao cargo de Presidente. No mesmo dia desses acontecimentos, agora na condição de advogada, Maria Rita solicitou a concessão de um mandato de segurança a favor de João Café Filho,

[...] para que cesse o impedimento por 172 dos 364 deputados e por uma maioria, também, precária, no Senado, a fim de que possa ele voltar a exercer em toda plenitude suas funções ocupadas, a esta hora, inconstitucionalmente, pelo Vice-Presidente do Senado, sr. Nereu Ramos [...] (DIÁRIO CARIOCA, 1955, p. 2).

\footnotetext{
${ }^{8}$ Ver: Carla Simone RODEGHERO (2006, p. 179-202).
} 
Pode-se observar que a trajetória política de Maria Rita foi marcada pela adesão a uma posição política conservadora, apropriando-se de um modelo feminino que exaltava a maternidade, a moralidade exemplar e a abnegação. Como sabemos, essa postura não era exclusiva de Maria Rita, mas fez parte da retórica de muitas mulheres que compuseram uma luta feminista na esfera estatal na primeira metade do século XX. A mulher nesses espaços precisava significar um símbolo da transformação de desigualdades, mas também da continuidade do que supostamente lhe era "mais próprio": a feminilidade, a maternidade e o cuidado da família.

Assim, a trajetória dessa militante é atravessada por constantes negociações no cenário político, sempre sob a retórica da mulher lutadora, sensível, católica e humana, características que apareciam na imprensa carioca como "prova" de sua qualidade como mulher. É fundamental destacar que esses usos certamente foram fundamentais para a vida pública de Maria Rita, já que essa "feminilidade", que simbolicamente representava a branquitude e a experiência de vida das mulheres de classe média e alta no Brasil, era recorrentemente dissociada da imagem das mulheres negras. A partir da pesquisa nos periódicos aqui utilizados foi possível observar os elementos que vão sendo mobilizados em torno da figura pública de Maria Rita, embora não tenhamos conseguido um maior número de informações sobre sua vida familiar para dispor de uma análise mais completa sobre esses elementos.

Para o Jornal do Brasil (1954a), ela "destacou-se durante a ditadura (1937-1945) como advogada militante, pela assistência prestada a perseguidos políticos de todo o País [...]" (p. 6). Isso aconteceu pois, apesar das posições políticas e ideológicas que marcaram as negociações realizadas por Maria Rita, estas não a impediram de defender pessoas acusadas de subversão ou de apoiar partidos opostos aos de sua filiação, principalmente quando eram favoráveis às suas alianças políticas.

Em 1952, Maria Rita solicitou ao Supremo Tribunal Federal um habeas corpus para dois militares acusados de atividades contrárias à segurança nacional (DIÁRIO CARIOCA, 1952, p. 12), assim como participou, em 1955, do encerramento da Convenção Nacional do Partido Socialista. Nesse ano, tal partido uniu-se à coalizão antigetulista liderada pelo general Juarez Távora, candidato apoiado pela UDN (DIÁRIO DE NOTíCIAS, 1955, p. 4). Em 1954, durante o período eleitoral, o escritor Odylo Costa FILHO (1954), do Diário de Notícias, aconselha o voto em Maria Rita para o cargo de deputada federal pois,

[...] esta mulher [...] não tem papas na língua. Nós a vemos todo o dia lutando, no esforço heroico de ganhar a vida. Nasceu paupérrima, fez-se pelas próprias mãos, tendo de enfrentar a força do preconceito. Sua consciência de católica é uma limpidez cristalina, que a fez enfrentar ontem o Tribunal de Segurança como advogada de alemães, que pagavam o mal da pátria e a fez hoje assumir a defesa de oficiais comunistas que faziam literatura e a polícia entendeu que conspiravam [...] (p. 2).

Outra ação política de Maria Rita que pudemos encontrar nas páginas dos jornais cariocas foi seu engajamento em favor do reingresso das mulheres aos postos diplomáticos. Em 1938, um decreto presidencial estabeleceu que somente os homens poderiam ingressar na carreira diplomática. Em 1946, o presidente Eurico Gaspar Dutra e o Ministro das Relações Exteriores, João Neves de Fontoura, revogam, portanto, o decreto-lei $n^{\circ} 9.202$ que vetava o acesso das mulheres ao Itamaraty. Entretanto, entre 1946-1954 não foi possível que ingressassem nos postos diplomáticos. O que aconteceu na prática foi, por um lado, as mulheres tentando prestar o exame de admissão, e, por outro, o Ministério das Relações Exteriores recusando sua admissão. Assim, a matrícula era negada às mulheres que haviam sido aprovadas nos concursos. 
No ano de 1952, Maria Rita é citada como advogada de Maria Sandra Cordeiro de Melo, que, protegida por uma liminar, prestou concurso de preparação à carreira diplomática. Maria Sandra foi aprovada e matriculou-se na $1^{\circ}$ série ainda no mesmo ano. Porém, Maria Rita teve que conduzir uma batalha judicial e parlamentar até o ano de 1954, pois o Ministério das Relações Exteriores, sem jurisprudência efetiva, continuava a vetar o acesso às mulheres.

O jornal Última Hora de 1953, declarando que Maria Rita instaurou uma verdadeira "guerra entre os sexos", intitulou um dos seus artigos com a seguinte frase: "Elas' tomaram o Tribunal de Assalto, mas os Ministros decidiram 'contra'" (p. 01). Tratava-se de um recurso formulado pela advogada Maria Rita que obteve votos negativos. Dessa maneira, a resolução ficaria a cargo do Poder Judiciário que, em 1954, concedeu à candidata Maria Sandra a possibilidade de frequentar as aulas do Instituto Rio Branco com um mandado de segurança liminar.

Além da área do direito e da política, Maria Rita também atuava destacadamente na área do jornalismo e foi autora de livros consagrados pela crítica. Ela apresentava um programa da Rádio Jornal do Brasil (1954b), Aprenda democracia (p. 08), no qual discutia tópicos sobre educação política. Maria Rita apoiou igualmente a criação da Ordem dos Jornalistas Brasileiros "[...] como órgão de seleção, defesa e disciplina da classe dos que militam na imprensa [...]" (DIÁRIO DA NOITE, 1955b, p. 3) ${ }^{9}$ e trabalhou em defesa da Imprensa Estudantil.

A militante participou ativamente dos movimentos de mulheres no início dos anos 1950; porém, durante a escrita desse artigo não foi possível saber se estabeleceu relações com os movimentos negros durante esse período.

Em 1946, o senador Hamilton Nogueira (UDN) propôs na Assembleia Nacional Constituinte um projeto de lei antidiscriminatória. Já havia no país um debate em torno da existência do preconceito racial, mesmo que esse ainda não questionasse diretamente o consenso em relação à ideologia da "democracia racial" (Jacques Edgard D'ADESKY, 2001, p. 135-137). ${ }^{10} \mathrm{Em} 1949$, o senador havia também sido premiado pelo Teatro Experimental do Negro (TEN) com a "Láurea Zumbi dos Palmares", destinada às personalidades que mais agiram no âmbito nacional em favor da valorização do negro (DIÁRIO CARIOCA, 1949, p. 6).

Maria Rita militou durante vários anos ao lado de Hamilton Nogueira, candidato a senador pela UDN nas eleições de 1954, fazendo parte também da chapa Aliança Popular. Hamilton foi citado várias vezes nos artigos dos jornais como um importante colaborador das pautas dos movimentos de mulheres, principalmente do Conselho Nacional de Mulheres (IMPRENSA POPULAR, 1954a, p. 5). Neste mesmo ano, nota-se no item cinco das proposições da Conferência Latino-Americana de Mulheres a pretensão de lutar contra os preconceitos e discriminações de sexo ou de raça (IMPRENSA POPULAR, 1954b, p. 13). Porém, Maria Rita se opôs a esta conferência que era de orientação comunista, assinando o Manifesto das Associações Femininas de Mulheres e Senhoras. No seu programa de rádio, afirmou:

[...] não sinto nem distingo bem essa história de classes: talvez por haver nascida na mais pobre e viver no meio de todas elas, aprendi por experiência que a resistência não é

\footnotetext{
9 $O$ objetivo da criação da Ordem dos Jornalistas era "[...] reduzir o espaço destinado à publicação de suicídios e crimes" (DIÁRIO DA NOITE, 1955a, p. 5).

10 Durante o governo de Vargas (1930-1945), foi elaborada no Brasil uma ideologia de harmonia entre as raças. A mestiçagem da população teria permitido uma igualdade entre todos os cidadãos. O livro Casa Grande e Senzala, de Gilberto Freyre, publicado em 1933, é uma obra que marca esse pensamento.
} 
monopólio dos bem situados na vida: na pobreza também se luta e resiste, e melhor, por vezes (JORNAL DO BRASIL, 1954b, p. 8).

É possível supor que Maria Rita não tenha aderido à luta antirracista a partir dos movimentos negros. Além disso, ela se afasta da ideologia da luta de classes, bastante difundida pelos teóricos marxistas e aceita por certos movimentos negros e movimentos de mulheres negras. Todavia, Maria Rita tinha consciência da necessidade dos grupos mais desfavorecidos, compostos principalmente por mulheres negras, de lutar por melhores condições de vida e contra a opressão e a exploração.

Maria Rita esteve em diferentes grupos, especialmente aqueles de filiação mais conservadora e que atuavam na política institucional. Sua trajetória esteve relacionada a conhecidos episódios da nossa história política. Apesar disso, sua presença não coube (e caberia?) nas narrativas hegemônicas da nossa historiografia, tão recorrentemente marcada pelas aparições públicas masculinas e de espaços, como o da governabilidade, que, apesar da presença das mulheres, são tão enraizadamente visibilizados como masculinos. Tampouco a trajetória de Maria Rita se situa nas narrativas hegemônicas dos feminismos brasileiros, seja pelas narrativas das "ondas feministas", seja pelos caminhos e filiações que marcam sua experiência. Os paradoxos e contradições que atravessam a vida dessa militante são interessantes para problematizarmos a complexidade das vivências e ações feministas, vividas na defesa de bandeiras coletivas ou na resistência cotidiana e individual.

\section{Mulheres negras comunistas: Maria Brandão e Maria Aragão}

No começo do século XX, várias mulheres negras aderiram ao Partido Comunista Brasileiro. Desde a década de 1930, a "questão da mulher" foi integrada às temáticas próprias do marxismo-leninismo. O comunismo pronunciava uma sociedade mais justa e, para isso, seria preciso lutar contra todas as formas de exclusão. Assim, movimentos de mulheres articulados com os movimentos de esquerda interrogavam sobre a condição das mulheres e, consequentemente, elaboravam várias críticas capazes de associar a exploração de classe à opressão de sexo.

Dessa forma, várias mulheres negras tiveram suas primeiras experiências políticas nos partidos de esquerda e, em seguida, iniciaram suas trajetórias no movimento de mulheres, lutando por direitos civis e contra as desigualdades sociais, e privilegiando ações que visavam a melhorias nas condições de vida da população (Tauana Olívia Gomes SILVA, 2014, p. 03).

Esse é o caso da Associação Feminina do Distrito Federal, proposta político-partidária que se multiplicou em outros estados do país. A entidade era formada por um núcleo de mulheres que, a partir de várias reuniões entre as associações estaduais, constituiu, em 1949, a Federação de Mulheres do Brasil. Desse modo, nesta segunda parte objetivamos analisar as trajetórias de duas mulheres negras comunistas, Maria José Camargo de Aragão e Maria Brandão do Reis, nesses movimentos de mulheres.

A AFDF, em 1950, lançou uma campanha contra a carestia na qual participaram várias militantes negras. A entidade contou com a colaboração das organizações femininas dos bairros e subúrbios a ela filiadas (MOMENTO FEMININO, 1950a, p. 12).

A Associação se interessou igualmente, em várias ocasiões, pelo problema da habitação e pelas dificuldades das mulheres moradoras dos morros e favelas. No jornal Momento Feminino - principal órgão de divulgação das atividades da FMB - um artigo aponta a precariedade da água, luz, assistência médica e escolas no morro Marquês de Abrantes. A autora assinala que 
a vida das mulheres, principalmente, é um tormento, um martírio constante. Nem mesmo sonham com o que seja conforto, carecendo de tudo que possa tornar a vida um prazer. [...] Foi uma felicidade, no entanto, podermos constatar que há muitas mulheres por ali, abrindo os olhos à realidade. Vimos, por exemplo, várias delas assistir a Conferência de uma delegada brasileira ao Congresso de Budapeste e promovida pela União Feminina Larangeira-Catete e Glória. Vimos também que as mulheres do Morro de Marquês de Abrantes enviarão uma delegada à Primeira Convenção Feminina a realizar-se dia 8 nesta cidade. [...] (MOMENTO FEMININO, 1949, p. 4).

Em 1950, o mesmo jornal assinala a vitória alcançada pelas mulheres da Associação Feminina da Baixa do Sapateiro ao impedirem a destruição de seus barracos. Elas organizaram diversos comícios e levaram comissões à Câmara Municipal, sendo apoiadas pelas comissões de solidariedade da AFDF (MOMENTO FEMININO, 1950b, p. 3).

Outro ponto abordado pela AFDF foi a

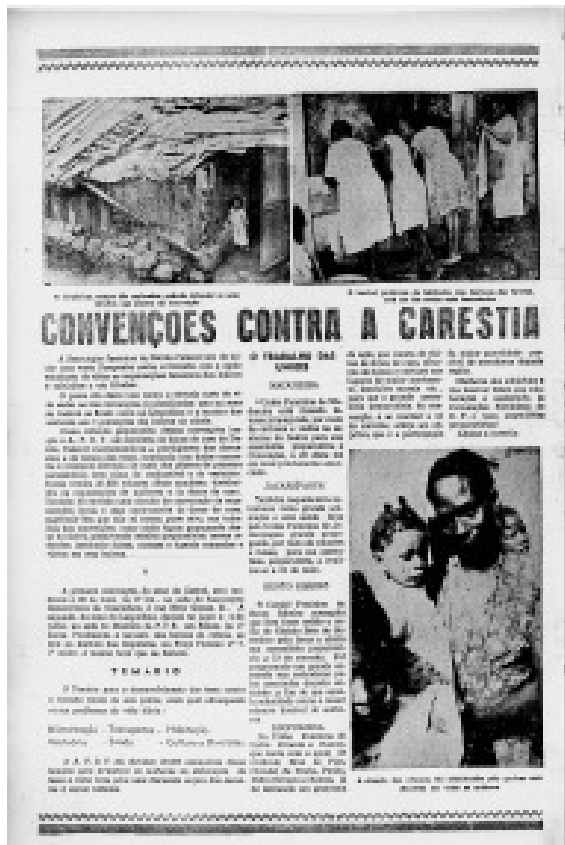

MOMENTO FEMININO. Rio de Janeiro, ano III, n. 69,18 de maio de 1950 a criação de comitês nas fábricas e uma dinâmica política em prol dos direitos das mulheres operárias. Em 1952, a organização apoiou a greve das tecelãs cariocas, assim como mobilizou suas delegadas para o Congresso Mundial de Mulheres (IMPRENSA POPULAR, 1953a, p. 4).

Maria Brandão dos Reis, militante do PCB e da FMB, seguindo essa linha de orientação política, participou ativamente na mobilização das moradoras das favelas de Salvador. Em 1947, ela apoiou as mulheres do bairro Corta Braço que estavam sendo ameaçadas de perderem suas casas. Maria também colaborou na organização de uma vigília noturna e uma passeata de protesto. Em 1950, se engajou na Campanha da Paz, organizada pelo PCB, incentivando a formação de conselho em vários municípios. Segundo o jornal Voz Operária, um dos objetivos do Congresso Nacional de Mulheres (1951) era a defesa da paz. Assim, as delegadas saíram nas ruas em busca de assinaturas para o "Apelo por um Pacto da Paz" (Ana MONTENEGRO, 1951, p. 4).

O jornal Momento Feminino informa que "dezenas de grupos de mulheres subiram aos morros, percorreram os bairros e foram às portas das fábricas" (MOMENTO FEMININO, 1951 b, p. 8). É possível notar a participação direta das mulheres negras, como Maria Brandão, nas diferentes fotografias que registraram as mobilizações (MOMENTO FEMININO, 1951 c, p. 5). O jornal ressaltou, no ano de 1950, o comando de coleta de assinatura realizado pela "União Feminina do Km. 8", em Fortaleza. Percebe-se na fotografia um grupo formado na maior parte por mulheres negras (MOMENTO FEMININO, 1950c, p. 4). ${ }^{11} \mathrm{Em} 1952$, elas são também numerosas no ato público realizado na sede do Movimento Carioca pela Paz.

\footnotetext{
${ }^{11}$ Essas mulheres colhiam assinaturas para o II Congresso Brasileiro dos Partidários da Paz.
} 
Durante esse período, Maria Brandão tornou-se destacada liderança no interior do PCB e da Federação de Mulheres do Brasil. Em Salvador, onde foi morar devido a seu envolvimento partidário, abriu uma pensão e transformou o local em grande reduto da militância política. "[...] Sua casa tem as portas abertas para aquele mundo de amigos, partidários da Paz" (MOMENTO FEMININO, 1951 d, p. 7). Além disso, Maria Brandão foi delegada estadual pela Bahia no III Congresso Brasileiro dos Partidários da Paz, que aconteceu na cidade do Rio de Janeiro, no ano de 1951. O Movimento da Paz baiano foi apontado pelo jornal Imprensa Popular como um dos mais desenvolvidos no país, contando com Conselhos Municipais em várias cidades. Maria Brandão, designada como "a milionária da paz" devido ao número de assinaturas que coletou para a campanha do $\mathrm{PCB}$, foi uma das responsáveis pela criação desses Conselhos Municipais (IMPRENSA POPULAR, 1951d, p. 1).

Durante esse evento Maria Brandão se sobressaiu como uma das sócias recordistas da FMB na coleta de assinaturas. O Momento Feminino (1951d), no artigo intitulado "Uma Recordista", aponta que a militante

[...] trouxe 10.700 assinaturas para o III Congresso Brasileiro dos Partidários da Paz. Para sabermos a maneira como conseguiu, ouçamos a palavra de Maria Brandão [...]: - Eu ouvia, sempre, diversas pessoas falarem de outra guerra e do envio de moços para a guerra da Coreia. Ficava preocupada. Pensava assim: milhares de vidas de jovens estão em perigo. Já fazia uma ideia das mães perdendo seus filhos, esposas ficando viúvas, irmãs sem seus irmãos e noivas sem seus noivos. Não, disse para minha filha, deve haver um meio de evitar tantas mortes. Foi quando ouvi falar no Apelo por um Pacto de Paz. E continuando: - Fui ao Comitê de Paz do meu bairro, mandaram que eu esperasse três dias, pois não havia listas. Mas resolvi não esperar tanto tempo. Mandei imprimir as listas por minha conta e no outro dia sai distribuindo nas casas dos amigos e conhecidos (p. 7).

Já o Voz Operária (1951b) se refere ao discurso de Maria Brandão durante o Congresso como "a voz das mães brasileiras".

Entre as intervenções das pessoas do povo, destacou-se a de d. Maria Brandão, uma sexagenária ${ }^{12}$ da Bahia, cujas palavras simples mas eloquentes exprimiram o profundo sentir das mães brasileiras. Já vivi minha vida, exclamou d. Maria Brandão. Luto pelos moços, pelas crianças, por tudo o que está nascendo (p.12).

Em 1952, Maria Brandão recebeu uma medalha de ouro do Júri Nacional dos Prêmios da Paz, conferida aos mais destacados coletores de assinaturas (VOZ OPERÁRIA, 1952, p. 4). A sua importante participação na Campanha de 1951 lhe rendeu a indicação de "Campeã da Paz". Contudo, ao se engajar nos movimentos políticos e nas atividades intelectuais, essas mulheres negras são personagens em ruptura com as funções que lhes foram atribuídas historicamente, como o servilismo visto como atributo natural caracterizado pela visão apresentada por Gilberto Freyre da negra, "ser-corpo-sexualizado" e "ser-corpo-trabalho" que foi construída na sociedade brasileira (Gilberto Freyre citado por Nubia Regina MOREIRA, 2011 , p. 26). Essas mulheres se insurgiram contra vários elementos da ordem estabelecida e lutaram para defender seus ideais.

Assim, Maria Brandão encontrou impetuosos obstáculos quando se destacou na militância política e foi indicada como "Campeã da Paz". As barreiras se tornaram ainda mais brutais quando se tratou de representar a Nação no exterior.

12 Há diferentes informações sobre a verdadeira idade de Maria Brandão. Em alguns artigos ela aparece como uma senhora de 60 anos e, em outros, como uma senhora de 70 anos. Segundo o Dicionário de Mulheres Negras do Brasil, ela nasceu no dia 22 de julho de 1900 (SCHUMAHER; BRAZIL, 2007, p. 317). 
A premiação deveria ocorrer em Moscou, mas Maria foi preterida de receber pessoalmente o prêmio, pois o partido achou por bem substituí-la por um jovem intelectual, o que gerou seu descontentamento com os líderes comunistas (Schuma SCHUMAHER; Erico Vital BRAZIL, 2007, p. 317-318).

Maria Brandão foi impedida de representar o país no exterior, sendo substituída por um homem. É possível pensar que não se tratava somente de uma atitude sexista do partido, pois, em 1953, Elisa Branco recebeu o Prêmio Internacional Stalin da Paz no Palácio do Kremlin, em Moscou. Depois da sua prisão por ter se manifestado contra o envio de soldados para a guerra da Coreia, ela tornou-se um símbolo internacional (MOMENTO FEMININO, 1952, p. 2). De toda maneira, só foi possível encontrar jornais sobre a nomeação de Elisa Branco. Nenhum documento foi encontrado em relação à indicação de Maria Brandão e seus feitos tornaram-se invisíveis na história do partido. Segundo bell hooks (1995, p. 467), esse tipo de invisibilidade seria resultado do racismo, do sexismo e da exploração de classe institucionalizada, que também impõe reais barreiras quando as mulheres negras decidem se inserir no espaço da resistência política e/ou do trabalho intelectual.

Dessa forma, mesmo se encontramos Maria Brandão dos Reis ao lado de Elisa Branco aclamando pelo povo e posando para as câmeras fotográficas dos jornais (IMPRENSA POPULAR, 1951 g, p. 7), mesmo se a advogada Maria Rita Soares de Andrade é citada com respeito como "uma senhora grisalha" (ÚLIMA HORA, 1953b, p. 6), e a médica Maria José Camargo de Aragão é citada como "ilustre médica patrícia" (IMPRENSA POPULAR, 1951e, p. 3), as militantes negras vivem quotidianamente com as discriminações de sexo e de raça. A ascensão social e econômica, por sua vez, não significava obrigatoriamente a isenção das diferentes formas de opressão, já que essas mulheres se posicionam contra a ordem estabelecida, lutam por visibilidade e direitos. Elas saem dos padrões que Ihes foram historicamente reservados, e, por conseguinte, foram normalmente impedidas de irem além do que lhes é incumbido.

Maria Brandão, por exemplo, além de ter sido tratada como incompetente e desqualificada quando Ihe foi negado o prêmio de "Campeã da Paz", sofreu também com o estereótipo da "mãe preta". O jornal Momento Feminino (1951 d) afirmou que

Maria Brandão é uma figura popular na cidade do Salvador. [...] É uma espécie de mãe de toda aquela gente e dos que chegam de fora. Tipo de baiana, preta, gorda, carinhosa, seu entusiasmo contagia e sua amizade é um conforto. Tem quase 70 anos a Maria Brandão, e é tão moça, tão cheia de vida, dessa vida pela qual ela luta, para que seja longa e feliz para todos (p. 7).

Como discutiu bell hooks (1995), refletindo sobre o termo "mãe preta" citado acima,

[...] essa imagem registra a presença feminina negra como significada pelo corpo, neste caso a construção de mulher como mãe, "peito", amamentando e sustentando a vida de outros. Significativamente, a proverbial "mãe preta" cuida de todas as necessidades dos demais, em particular dos mais poderosos. Seu trabalho caracterizase pelo serviço abnegado. [...] Coletivamente, muitas negras internalizam a ideia de que devem servir, estar sempre prontas para atender, quer queiram quer não, à necessidade de outra pessoa (p. 469-470).

O jornal Imprensa Popular (1951f), depois de saudar Elisa Branco, apontada como a heroína da Paz, citou Maria Brandão como a preta velha que usou da palavra na III Sessão Plenária do Congresso.

Eis um lindo trecho de seu discurso: 'Se fosse por mim eu não lutaria mais, pois estou no fim da existência. Eu luto é por todas as crianças, por tudo aquilo que esta nascendo. No meu bairro me chamam de mãe Maria. Eu sou a mãe de vocês todos. Lutarei até a 
morte para defender a vida dos meus filhos queridos, que são todos os partidários da Paz' (p. 3).

A médica Maria Aragão assinalou também como conseguiu se impor como profissional nas classes mais altas de São Luiz.

Foi ainda sob o calor da campanha pela anistia em 1945, que Maria Aragão chegou em S. Luiz, depois de alguns anos de ausência da terra natal. Havia ingressado no Partido e voltava cheia de esperança no futuro para, não só exercer sua profissão de médica, como para dedicar a maior parte de sua vida às grandes lutas do proletariado. [...] Mantém um posto médico no bairro operário do Anil, onde receita e distribui remédios para os pobres. Ao chegar em S. Luiz improvisou seu consultório no modesto quarto da pensão, onde se hospedara. Sua clientela continuava a mesma dos subúrbios. Mais tarde vimos senhoras ricas a procurá-la. Maria nos explicou: - As patroas mandavam as empregadas se receitarem comigo. Acontecia que ficavam curadas e isto era uma boa propaganda. As patroas passaram a me procurar, daí a razão de muitas clientes ricas (Odete VIEIRA, 1951, p. 2).

No quinto aniversário do Teatro Experimental do Negro (TEN), foram atribuídas cinco láureas às personalidades - "de qualquer raça ou cor" - que mais contribuíram para valorização do negro e para a harmonia entre as raças. Nota-se, portanto, que a mulher negra é premiada somente nas láureas referentes ao âmbito familiar e artístico. Às personalidades femininas foram conferidas a "Láurea Mãe Preta" e a "Láurea Dragão do Mar". A primeira láurea, destinada à mulher que mais se sobressaiu nas atividades em favor da "mulher de cor", coube à Mary Mac Leod Betruna, educadora e presidente do Conselho Nacional das Mulheres Negras dos Estados Unidos. A segunda láurea, direcionada às personalidades que mais colaboraram para a causa do teatro negro no Brasil, coube à atriz Ruth de Souza, do TEN.

Os outros três prêmios que faziam referências diretas às atividades intelectuais e políticas, láurea Luiz Gama, láurea Zumbi dos Palmares e láurea Cruz e Souza, destinados a escritores e jornalistas, foram atribuídos a personalidades masculinas. Os ganhadores foram: Dr. Ralph J. Bunche, pela sua atuação pacificadora na Palestina; o senador Hamilton Nogueira, pela sua ação política no âmbito nacional e o professor Artur Ramos (DIÁRIO CARIOCA, 1949, p. 6).

Todavia, essas atitudes racistas e sexistas sofridas por Maria Brandão não causaram sua ruptura total com as organizações. Ao contrário, ela continuou a confirmar a tônica do seu empenho na militância política. Aos 64 anos, Maria Brandão ainda sofria com as perseguições políticas durante a ditadura militar de 1964-1984 e foi fortemente reprimida pelos regimes autoritários, assim como Maria Aragão (SCHUMAHER; BRAZIL, 2007, p. 318).

Nos anos 1950, Maria José Camargo de Aragão, militante do PCB e da FMB, foi presa e processada sob a acusação de atividades subversivas. O jornal Imprensa Popular (1951f) informa que Maria Aragão havia sido indicada "como cabeça do movimento oposicionista e insufladora dos acontecimentos que abalaram a capital maranhense [...]" (p. 3). Entre fevereiro e outubro de 1951, aconteceu uma greve conhecida como "Balaiada de São Luiz" que representou um movimento amplo, radical e heterogêneo, mobilizando a população revoltada com as práticas fraudulentas do coronel Vitorino Freire. A greve ocorreu em razão dos desdobramentos da disputa pelo governo estadual entre as forças políticas oligárquicas ligadas ao senador Vitorino Freire (PST) e das "Oposições Coligadas" (PR, UDN, PSD, PL, PSP, PTB), representativas de outros setores oligárquicos.

Vitorino Freire havia rompido com o processo eleitoral garantindo a vitória do seu candidato, Eugênio de Barros. Porém, a população de São Luís, influenciada pelos 
opositores, reagiu de forma violenta a essa fraude. Grupos de populares promoveram nas ruas atos de repúdio e protesto. Em janeiro de 1951, morre o candidato das "Oposições Coligadas" Saturnino Belo, e, em fevereiro de 1951, Eugênio de Barros toma posse do Governo do Estado instaurando uma repressão feroz contra as populações da capital e do interior. A cidade de São Luiz ficou totalmente paralisada e generalizaram-se os conflitos.

Nesse contexto de violência, Maria Aragão é acusada de participação ativa nos acontecimentos e também encarcerada. Para o Imprensa Popular:

"[...] Nos comícios [...], praças e subúrbios de S. Luiz, ela se fez logo grande oradora e intérprete das massas. [...] Seu nome é respeitado e inspira confiança, não só como médica mas como uma sincera lutadora contra a opressão, a miséria e a fome (VIEIRA, 1951, p. 2).

Durante a prisão, Maria Aragão recebeu um grande apoio de muitos médicos e de parte da Federação de Mulheres do Brasil, que se dirigiu ao governador maranhense Eugênio de Barros exigindo sua liberação.

A Federação de Mulheres do Brasil [...] vem [...] trazer seu protesto contra as arbitrariedades [das] medidas praticadas pela policia, [...] contra a dra. Maria José Aragão, mantida no cárcere [...] sob acusações de ter patrocinado atos de incêndios nessa cidade. [...] A FMB conhece a situação da mulher maranhense, da sertaneja ou praiana [...]. Nenhuma mulher, principalmente com os princípios de fraternidade que sabemos reger a vida da dra. Maria Aragão poderá ser arrasada a um crime de tal natureza, para deixar ao desabrigo e em maiores privações a centenas de famílias. Neste protesto, [...] milhares de senhoras que trabalham arduamente na Federação, todas unidas neste momento a pedir liberdade e arquivamento do processo de dra. Maria José Aragão (IMPRENSA POPULAR, 1951e, p. 3).

A participação de Maria Aragão nas atividades do jornal já era bastante conhecida antes da sua prisão e é assinalada na Comissão da Campanha de Ajuda à Imprensa Feminina, organizada pelo Momento Feminino (1951 a, p. 6) para a arrecadação de contribuições financeiras. Logo após, ela também foi uma das campeãs em número de vendas de exemplares do jornal.

Dessa maneira, quebrando a incomunicabilidade da prisão, Maria Aragão conseguiu enviar ao jornal Imprensa Popular um telegrama de saudação patriota à data que assinalava a vitória da Revolução Socialista de Outubro. O texto dizia: "Saudando este 7 de novembro, reafirmo a minha inabalável fé na vitória do povo brasileiro em sua luta pela conquista da Paz e da libertação nacional" (IMPRENSA POPULAR, 1951f, p. 3). A médica maranhense recebeu, em seguida, o apoio do presidente da Associação Brasileira de Imprensa, que também se dirigiu ao governador do Maranhão solicitando sua liberação. Maria Aragão era uma personalidade bastante importante na área do jornalismo. Como diretora do jornal Tribuna do Povo, de São Luiz, participou ativamente da Comissão Nacional da Campanha de Ajuda aos Jornais de Prestes e da Frente Democrática de Libertação Nacional (VOZ OPERÁRIA, 1951a, p. 12).

Em 10 de outubro de 1951, após a profusão de protestos e do sentimento de indignação por parte de vários setores da sociedade contra a prisão da líder comunista, Eugênio de Barros assegurou que tomaria providências no sentido de libertá-la, questão que deve ser ressaltada pois tratava da libertação de uma mulher negra e comunista fruto de contestação popular (IMPRENSA POPULAR, 1951c, p. 2). No entanto, no dia 30 de outubro, o governador respondeu para a Associação Brasileira de Imprensa que

[...] em favor da médica dra. Maria Aragão, apresso-me informar [que se] estivesse o assunto em minha alçada não hesitaria em atender ao nobilitante apelo sem considerar 


\begin{abstract}
a circunstância de que a coação que sofre a mesma senhora é decorrente não dos sagrados misteres da imprensa mas de ostensiva atividade de propaganda do extinto Partido Comunista, agitação subversiva a que se entregava no curso dos recentes e graves acontecimentos nesta capital, conduta que ocasionou sua prisão em flagrante [...]. Infelizmente no momento a questão se acha pendente no judiciário [...] e [...] o Tribunal denegou pedido de "habeas-corpus". Impedindo, precisamente no interesse de patentear a isenção e fidelidade a que se refere o ilustre patrício, de qualquer interferência no caso, asseguro entretanto a solicitude e mesmo o grande prazer com que farei cumprir a decisão que reponha em liberdade a dra. Aragão (DIÁRIO DE NOTÍCIAS, 1951, p. 4).
\end{abstract}

A imediata liberação de Maria Aragão provavelmente não era uma razão para o governador Eugênio de Barros rejubilar. Ela não somente era considerada uma das mais importantes personalidades comunistas do estado, como também se opôs ao conúbio entre governo e "oposições". Em diferentes circunstâncias Maria Aragão foi considerada a verdadeira heroína do movimento de resistência política contra o sistema oligárquico do Maranhão. Em 1951, o jornal Imprensa Popular afirmou que

\begin{abstract}
Maria simboliza a revolta daquele Estado, traiçoeiramente abafada [...]. Com ela, esses tiranos e traidores aprisionaram a própria revolução maranhense, que não se extinguiu, porém, porque a grande prisioneira, do seu cárcere, continua a lutar pela paz e contra o governo de fome, guerra e opressão [...]. É de urgência, portanto, que se intensifique a luta pela libertação dos nossos lideres, das nossas heroínas. [...]. Aproveitemos essas experiências adquiridas e arranquemos do cárcere, Maria Aragão, a grande médica, consequente lutadora e querida dirigente do povo maranhense (VIEIRA, 1951, p. 2).
\end{abstract}

Devido à situação de violência na qual Maria Aragão se encontrou durante a prisão, sua saúde também se deteriorou. Depois de ser posta em liberdade, ela teve que ir até o Rio de Janeiro para tratamentos médicos. Porém, a militante continuou a se dedicar à defesa da democracia, da liberdade e à implantação do partido no Maranhão. Em 1953, ela esteve entre um grupo de intelectuais, líderes sindicais, juvenis e femininas que se dirigiram a várias entidades soviéticas para saudar a Revolução de Outubro de 1917 (IMPRENSA POPULAR, 1953b, p. 3). No mesmo ano seu nome foi citado em um artigo sobre o desmantelamento de uma célula comunista no Rio de Janeiro. A polícia havia encontrado trocas de mensagens e boletins entre a polonesa Miriam Nisel Shargel, presa por atividades subversivas, e Maria Aragão (ÚLTIMA HORA, 1953a, p. 5), que alguns anos depois, em 1955, tornou-se chefe do PC do Maranhão. Durante a ditadura militar de 1964-1984, foi presa e torturada três vezes, consagrando-se uma das maiores líderes políticas do seu estado.

\title{
Considerações finais
}

O objetivo desse texto nem de longe é dar conta das vivências das mulheres negras e do feminismo negro no Brasil. Através das experiências de vida e de luta das mulheres que escolhemos para discutir nestas poucas linhas, buscamos fazer um chamamento para a importância de visibilizar, explorar e questionar a forma com que as lutas sociais são contadas historicamente no Brasil. As narrativas sacralizadas e oficiais na nossa historiografia precisam ser revisitadas, rediscutidas, e suas escalas e táticas precisam ser relidas à luz da luta pelo reconhecimento e pela sobrevivência que muitas sujeitas sociais precisam travar.

Partindo dessa pesquisa inicial, portanto, gostaríamos de destacar duas reflexões historiográficas nas quais esse artigo pode contribuir: a primeira se refere à história política no Brasil sob a perspectiva da história das mulheres, que há algumas décadas busca demonstrar a existência e a participação das mulheres em vários processos históricos que 
são narrados no masculino e a partir de figuras masculinas. Situadas nessa perspectiva, acreditamos que a visibilidade das experiências dessas mulheres pode nos ajudar a entender os diferentes processos de (in)visibilidade política que muitas vivenciaram, e, como vimos na trajetória dessas mulheres negras, não se faz pela ausência das mulheres nos já conhecidos episódios da nossa história política, mas por outros elementos, como o gênero, a raça, a classe, a sexualidade, o estado civil que marcam essas trajetórias. Afinal, nunca é bastante perguntar: que sujeitos(as) visibilizamos quando interpretamos a história política do Brasil?

A segunda reflexão se refere às narrativas da história dos feminismos que ainda classifica esses movimentos e ideias em "ondas". Acreditamos que é necessário e urgente alargar essas narrativas, pois cada vez mais elas parecem insuficientes para abarcar a diversidade das práticas que podem ser consideradas feministas, assim como suas pautas, sujeitas e identidades. As lutas cotidianas e as ações coletivas realizadas por muitas mulheres, como as mulheres negras comunistas na metade do século $\mathrm{XX}$, são centrais nessas experiências e em muitos casos não se enquadram na narrativa oficial das "ondas feministas".

As histórias de Maria Rita, Maria Aragão e Maria Brandão, rapidamente aqui discutidas, são apenas algumas das muitas histórias de mulheres negras que compuseram as lutas por direitos sociais, por reconhecimento profissional, contra as desigualdades de classe, pela melhoria de profissões como a das trabalhadoras domésticas, pela melhoria da vida daqueles e daquelas da favela e, principalmente, pela luta da palavra, pelo direito de fala e de escuta, e que ainda não aprendemos a reconhecer ou a escutar.

Acreditamos que a experiência dessas mulheres no movimento de mulheres, nos partidos comunistas, filiando-se a diferentes posturas e preceitos ideológicos nos ajuda não apenas a expandir a noção de "ondas feministas", mas principalmente nos traz reflexões sobre o que significa ser feminista na sociedade brasileira. Muitas dessas mulheres reforçaram, por exemplo, o tema da maternidade, que mais do que uma tática política largamente explorada no feminismo da primeira metade do século XX, ao ser pensado na historicidade da experiência das mulheres negras, pode e deve ganhar outras reflexões e problemáticas. Como sabemos, para estas, o cuidado dos próprios filhos e filhas foi atividade por vezes negada em benefício dos filhos e filhas das mulheres brancas que poderiam (e ainda podem) pagar por seus serviços de cuidados. Perguntamos: o que significa, portanto, o reforço ou mesmo a desconstrução do aspecto da maternidade, por exemplo, na experiência de vida dessas mulheres que possuem marcas e lutas históricas específicas?

Refletir sobre as vivências e as lutas das mulheres negras, das mulheres indígenas, das mulheres que estão imersas nas mais diferentes regiões do que convencionamos chamar de Brasil pode não apenas possibilitar novas narrativas da história das mulheres, mas também e, principalmente, nos ajudar a deslocar a ideia do que é ser feminista. Afinal, também nunca é bastante perguntar, o que é feminismo? O que é ser feminista quando consideramos corpos e histórias diferentes?

Nesse sentido, concluímos este artigo com a ideia de que a luta das mulheres negras na metade do século passado aponta para muitos temas, ideologias, alianças e espaços de militância e, por isso mesmo, elas precisam, cada vez mais, ser analisadas e pensadas dentro de sua historicidade. Além disso, para além de serem pensadas como outras narrativas, elas possuem um potencial de nos trazer questões para algumas verdades da nossa história e dos nossos feminismos. 


\section{Referências}

CORREIO DA MANHÃ. Rio de Janeiro, ano 19, n. 18024, 22 de dezembro de 1951. CORREIO DA MANHÃ. Rio de Janeiro, ano LIV, n. 18824, 7 de agosto de 1954, $1^{\circ}$ Caderno. D'ADESKY, Jacques Edgard. Racismeset antiracismes au Brésil. Paris: L'Harmattan, 2001. DIÁRIO CARIOCA. Rio de Janeiro, ano XXII, n. 6524, 1 de outubro de 1949. DIÁRIO CARIOCA. Rio de Janeiro, ano XXV, n. 7471, 8 de novembro de 1952. DIÁRIO CARIOCA. Rio de Janeiro, ano XXVIII, n. 8393, 23 de novembro de 1955. DIÁRIO DA NOITE. Rio de Janeiro, seção 01, ano XXVII, n. 5858, 15 de abril de 1955a. DIÁRIO DA NOITE. Rio de Janeiro, seção 01, ano XXVII, n. 5855, 6 de agosto de 1955b. DIÁRIO DE NOTÍCIAS. Rio de Janeiro, ano XXII, n. 8900, 30 de outubro de 1951. DIÁRIO DE NOTíCIAS. Rio de Janeiro, seção 01, n. 9989, 31 de maio de 1955. DOMINGUES, Petrônio. "Movimento Negro Brasileiro: alguns apontamentos históricos". Tempo, São Paulo, v. 12, n. 23, p. 100-122, 2007.

FILHO, Odylo Costa. "Encontro Matinal. Candidatos", Diário de Notícias, Rio de Janeiro, primeira seção, ano XXV, n. 9784, p. 02, 25 de setembro de 1954.

hooks, bell. "Intelectuais Negras". Revista Estudos Feministas, Rio de Janeiro, IFCS/UFRJ e PPCCIS/UERJ, v. 3 n. 2, p. 464-478, 1995.

IMPRENSA POPULAR. Rio de Janeiro, ano IV, n. 589, 5 de janeiro de 1951 a. IMPRENSA POPULAR. Rio de Janeiro, ano IV, n. 749, 29 de julho de $1951 \mathrm{~b}$. IMPRENSA POPULAR. Rio de Janeiro, ano IV, n. 905, 10 de outubro de 1951 c. IMPRENSA POPULAR. Rio de Janeiro, 20 de outubro de 1951d, ano IV, n. 904. IMPRENSA POPULAR. Rio de Janeiro, ano IV, n. 906, 23 de outubro de 1951 e. IMPRENSA POPULAR. Rio de Janeiro, ano IV, n. 920, 8 de novembro de $1951 \mathrm{f}$. IMPRENSA POPULAR. Rio de Janeiro, ano IV, n. 927, 18 de novembro de 1951 g. IMPRENSA POPULAR. Rio de Janeiro, ano VI, n. 1387, 3 de abril de 1953a. IMPRENSA POPULAR. Rio de Janeiro, ano VI, n. 1649, 8 de novembro de 1953b. IMPRENSA POPULAR. Rio de Janeiro, ano VII, n. 1282, 21 de agosto de 1954a. IMPRENSA POPULAR. Rio de Janeiro, ano VII, n. 1295, 5 de setembro de 1954b. JORNAL DO BRASIL. Rio de Janeiro, ano LXIV, n. 97, 29 de abril de 1954a, $1^{\circ}$ Caderno. JORNAL DO BRASIL. Rio de Janeiro, ano LXIV, n. 171, 27 de julho de 1954b. JORNAL DO BRASIL. Rio de Janeiro, ano LXIV, n. 251, 29 de outubro de 1954c. LEITE, Miriam Moreira. Outra face do feminismo: Maria Lacerda de Moura. São Paulo: Ática, 1984.

MOMENTO FEMININO. Rio de Janeiro, ano III, n. 69, 18 de maio de 1950a.

MOMENTO FEMININO. Rio de Janeiro, ano III, n. 73, 1 de agosto de $1950 \mathrm{~b}$.

MOMENTO FEMININO. Rio de Janeiro, ano III, n. 77, 20 de outubro de 1950c.

MOMENTO FEMININO. Rio de Janeiro, ano III, n. 81, fevereiro de 1951a.

MOMENTO FEMININO. Rio de Janeiro, ano III, n. 84, maio de $1951 \mathrm{~b}$.

MOMENTO FEMININO. Rio de Janeiro, ano III, n. 85, julho de $1951 \mathrm{C}$.

MOMENTO FEMININO. Rio de Janeiro, ano III, n. 89, dezembro de $1951 \mathrm{~d}$.

MOMENTO FEMININO. Rio de Janeiro, ano VI, n. 97, dezembro de 1952.

MONTENEGRO, Ana. "Para o I Congresso Nacional de Mulheres", Voz Operária, Rio de Janeiro, ano III, n. 113, 21 de julho de 1951c.

MOREIRA, Nubia Regina. Organização das feministas Negras no Brasil. Vitória da Conquista: UESB, 2011.

PEDRO, Joana Maria. "A emergência da pesquisa Histórica das Mulheres e das Relações de Gênero". Revista Brasileira de História, São Paulo, v. 27, n. 54, p. 281-300, 2007. 
PEREIRA, Amilcar Araujo. "O mundo Negro": a constituição do movimento negro contemporâneo no Brasil (1970-1995). 2010. Tese (Doutorado). Instituto de Ciências Humanas e Filosofia. Departamento de História, Universidade Federal Fluminense Niterói.

PINA, Avelina Iglesias. "Vida de misérias, a das mulheres do Morro Marquês de Abrantes", Momento Feminino, 8 de março de 1949, p. 04.

RODEGHERO, Carla Simone. "O anticomunismo nas encruzilhadas do autoritarismo e da democracia: a conjuntura 1945-1947". MÉTIS: história \& cultura, v. 5, n. 10, p. 179-202, jul./dez. 2006.

SCHUMAHER, Schuma; VITAL BRAZIL, Erico. Mulheres Negras do Brasil. 1.ed. Rio de Janeiro: SENAC NACIONAL História do Brasil, 2007.

SILVA, Tauana Olívia Gomes. "A participação política das mulheres negras comunistas nos movimentos de esquerda durante a ditadura militar". 2014. In: II SEMINÁRIO INTERNACIONAL HISTÓRIA DO TEMPO PRESENTE, 13 a 15 de outubro de 2014, Programa de Pós-Graduação em História (PPGH), Universidade do Estado de Santa Catarina (UDESC). Anais... Florianópolis. Disponível em: http://eventos.udesc.br/ocs/index.php/STPII/ tempopresente/paper/viewFile/181/115. Acesso em: 02/ 06/2015.

[Recebido em 26/10/2015,

reapresentado em $21 / 09 / 2016$

e aprovado em 09/01/2017]

And the Black Women? Historical Narratives of Feminism Out of the Waves

Abstract: This paper aims to think about the following questions: where are the spaces for black women in the prevailing narratives regarding women's movements and feminists movements in Brazil? To what extent do the theoretic limits and the methodologic paths that compose the most part of the feminist historiography and the women's struggle during the first half of the XX century in Brazil didn't allow us, or were not enough to try to understand and to reflect the struggles of black women? And lastly, what is the history of the agenda and feminist claims? How is this history told? Keywords: History of Feminism; Black Women; Trajectories of Life

Tauana Olívia Gomes Silva (tauana_hist@yahoo.com.br) é graduada em História pela Universidade Vale do Rio Doce-MG (2005) e pela Université Rennes 2-França (2008). Possui mestrado em História e Relações Internacionais pela Université Rennes 2 (2010) convenção com a Universidade Federal de Santa Catarina (2009). Atualmente é doutoranda em História na Université Rennes 2, em cotutela com a Universidade Federal de Santa Catarina. Atua principalmente nos seguintes temas: História das Mulheres Negras, Feminismo Negro, Relações de Gênero e Raciais.

Gleidiane de Sousa Ferreira (gleidiane cultura@hotmail.com) é graduada em História pela Universidade Federal do Ceará (2010). Possui mestrado em História Cultural pela Universidade Federal de Santa Catarina (2014). Atualmente é doutoranda em História Cultural na Universidade Federal de Santa Catarina. Atua principalmente nos seguintes temas: Feminismo, História das Mulheres, Relações de Gênero, Sexualidade, Movimentos Sociais e América Latina. 